\title{
Review \\ Developments in the scientific understanding of osteoarthritis
} Steven B Abramson and Mukundan Attur

Division of Rheumatology, NYU School of Medicine, NYU Hospital for Joint Diseases, East 17th Street, New York, NY 10003, USA

Corresponding author: Steven Abramson, StevenB.abramson@nyumc.org

Published: 19 May 2009

This article is online at http://arthritis-research.com/content/11/3/227

(c) 2009 BioMed Central Ltd
Arthritis Research \& Therapy 2009, 11:227 (doi:10.1186/ar2655)

nodal OA was twice as likely to occur in first-degree relatives as in control individuals. Twin pair and family risk studies have indicated that there is a significantly higher concordance for $\mathrm{OA}$ between monozygotic twins than between dizygotic twins, and that the hereditable component of OA may be in the order of $50 \%$ to $65 \%$ [2]. However, because of the prevalence of $\mathrm{OA}$ in the general population and extensive clinical heterogeneity, the precise genetic contribution to the pathogenesis of OA has been difficult to analyze. Moreover, it is clear that multiple genetic factors can contribute to the incidence and severity of $\mathrm{OA}$, and that these may differ according to specific joint (hand, hip, knee, or spine), sex, and race. There is also evidence, given the variety of candidate genes that predispose to $\mathrm{OA}$, that there may be an additive effect of individual genes in the development of disease [3].

\section{Introduction}

Osteoarthritis $(\mathrm{OA})$ is characterized by a progressive loss of articular cartilage accompanied by new bone formation and, often, synovial proliferation that may culminate in pain, loss of joint function, and disability. A variety of etiologic risk factors and pathophysiologic processes contribute to the progressive nature of the disease and serve as targets of behavioral and pharmacologic interventions. Risk factors such as age, sex, trauma, overuse, genetics, and obesity can each make contributions to the process of injury in different compartments of the joint. Such risk factors can serve as initiators that promote abnormal biochemical processes involving the cartilage, bone, and synovium, which over a period of years result in the characteristic features of OA: degradation of articular cartilage, osteophyte formation, subchondral sclerosis, meniscal degeneration, bone marrow lesions, and synovial proliferation.

\section{Risk factors for osteoarthritis Genetic predisposition}

A genetic disposition to $O A$ has been clear since it was first reported by Kellgren and coworkers [1] that generalized
Several candidate genes encoding proteins of the extracellular matrix of the articular cartilage have been associated with early-onset OA [4]. In addition to point mutations in type II collagen [5], inherited forms of OA may be caused by mutations in several other genes that are expressed in cartilage, including those encoding types IV, V, and VI collagens, as well as cartilage oligomeric matrix protein (COMP) [6].

Candidate genes for OA have also been identified that are not structural proteins. Among such candidates are the secreted frizzled-related protein 3 , asporin, and von Willebrand factor genes $[7,8]$. In follow-up studies it has been reported that the asporin, frizzled-related protein 3 , and von Willebrand factor genes have now been found not to replicate in large Caucasian meta-analyses and that the association with growth differentiation factor (GDF)-5 in Caucasians has been confirmed in larger meta-analyses [9-12]. Finally, evidence from mouse models indicates that genetic disorders affecting the architecture of subchondral bone can cause OA. Mice with a null mutation of the latent

ADAMTS $=$ a disintegrin and metalloprotease with thrombospondin motifs; CCR = C-C chemokine receptor; COMP = cartilage oligomeric matrix protein; $\mathrm{COX}=$ cyclo-oxygenase; CTX-II = carboxyl-terminal cross-linking telopeptide of type II collagen; ICE = IL-1 $\beta$-converting enzyme; IL = interleukin; iNOS = inducible nitric oxide synthase; MMP = matrix metalloproteinase; MRI = magnetic resonance imaging; OA = osteoarthritis; RANTES = regulated on activation, normal T-cell expressed and secreted; TACE $=$ TNF- $\alpha$-converting enzyme; TGF $=$ transforming growth factor; TNF $=$ tumor necrosis factor. 
transforming growth factor (TGF)- $\beta$ binding protein- 3 , which regulates the activation of TGF- $\beta$, developed both osteosclerosis and OA [13]. In addition, a recent report demonstrated that a genetic defect of type I collagen resulted in rapidly progressive OA in a mouse model [14].

In recent population studies, genome-wide linkage scans have highlighted several specific genes involved in disease risk [15]. Chromosome 2q was positive in several scans, suggesting that this chromosome is likely to harbor one or more susceptibility genes. Two IL-1 genes (IL1 $\alpha$ and IL $1 \beta)$ and the gene encoding IL-1 receptor antagonist (IL1RN), located on chromosome 2 q13 within a 430-kilobase genomic fragment, have been shown to associate with the development of primary knee, but not hip, OA [16]. IL1RN haplotype variants have also been shown to associate with radiographic severity of the OA [17]. Recently, a genomewide association scan has identified a cyclo-oxygenase (COX)-2 variant involved in risk for knee OA [18]. These genetic associations of genes such as IL1 $\alpha, I L 1 \beta, I L 1 R N$, and COX2 underscore the potential role of inflammatory pathways in the pathogenesis of knee OA.

\section{Age}

Age is the risk factor most strongly correlated with $O A$, and therefore understanding age-related changes is essential. Age-related mechanical stress on joint cartilage may arise from a number of factors, including altered gait, muscle weakness, changes in proprioception, and changes in body weight. In addition, age-related morphologic changes in articular cartilage are most likely due to a decrease in chondrocytes' ability to maintain and repair the tissue. This is because chondrocytes themselves undergo age-related decreases in mitotic and synthetic activity, exhibit decreased responsiveness to anabolic growth factors, and synthesize smaller and less uniform large aggregating proteoglycans and fewer functional link proteins [19]. Age also appears to be an independent factor that predisposes articular chondrocytes to apoptosis, because the expression levels of specific proapoptotic genes (those encoding Fas, Fas ligand, caspase-8, and p53) are higher in aged cartilage $[20,21]$.

\section{Obesity}

Obesity is another important risk factor for OA [22]. An increase in mechanical forces across weight-bearing joints is probably the primary factor leading to joint degeneration. The majority of obese patients exhibit varus knee deformities, which result in increased joint reactive forces in the medial compartment of the knee, thereby accelerating the degenerative process [23]. Emerging data implicate a crucial role for adipocytes in regulation of cells present in bone, cartilage, and other tissues of the joint. The comparatively recently discovered protein leptin may have important involvement in the onset and progression of $\mathrm{OA}$, and increase our understanding of the link between obesity and OA [24]. In addition, adipocyte-derived factors such as IL-6 and C- reactive protein appear to be pro-catabolic for chondrocytes. Further work is needed to determine whether leptin or other adipokines are important systemic or local factors in the link between obesity and OA.

\section{Joint malalignment}

Whether joint malalignment leads to the development of $\mathrm{OA}$ is a matter of debate [25]. However, the evidence does indicate that varus or valgus deformities are markers of disease severity and are associated with risk for progression of knee OA [26]. Indeed, there is evidence to suggest that much of the effect of obesity on the severity of medial compartment knee $\mathrm{OA}$ can be explained by varus malalignment [27]. Hunter and colleagues [28] have reported that enlarging or new bone marrow lesions occurred mostly in malaligned limbs, on the side of the malalignment. With regard to mechanisms, altered joint geometry may interfere with nutrition of the cartilage, or it may alter load distribution, either of which may result in altered biochemical composition of the cartilage [29].

\section{Sex}

Although hip OA is slightly more common in men, there is a marked increase in prevalence among women after the age of 50 years, particularly in the knee, and the cause of this increase - which has been ascribed to estrogen insufficiency is poorly understood [30]. Articular chondrocytes possess functional estrogen receptors, and there is evidence that estrogen can upregulate proteoglycan synthesis [31]. In support of a role for estrogens in OA, there are human and animal studies indicating that estrogen replacement therapy reduces the incidence of $\mathrm{OA}[32,33]$, although prospective randomized trials to confirm these observations, particularly with respect to structure modification, have not been performed. It should be noted, however, that the evidence for a relation between estrogen deficiency and OA in women is inconsistent, and one 4-year study showed no effect of estrogen plus progestin versus placebo on symptoms or disability in postmenopausal women [34].

\section{The pathobiology of osteoarthritis Biomechanics and loading: chondrocytes as mechano-sensors}

Chondrocytes embedded within the negatively charged cartilaginous extracellular matrix are subjected to mechanical and osmotic stresses [35-37]. One of the most exciting emerging areas is that chondrocytes, like osteocytes in bone, serve as mechano-sensors and osmo-sensors, altering their metabolism in response to local physicochemical changes in the microenvironment. Therefore, while obesity and joint misalignment are risk factors for $\mathrm{OA}$ in specific joints, the mechanism by which these risk factors initiate and perpetuate $\mathrm{OA}$ is largely mediated by biochemical pathways. Several groups have identified osmo-sensors and mechano-sensors in chondrocytes in the form of several ion channels, sulfate transporters and integrins [35-37]. In response to mechanical 


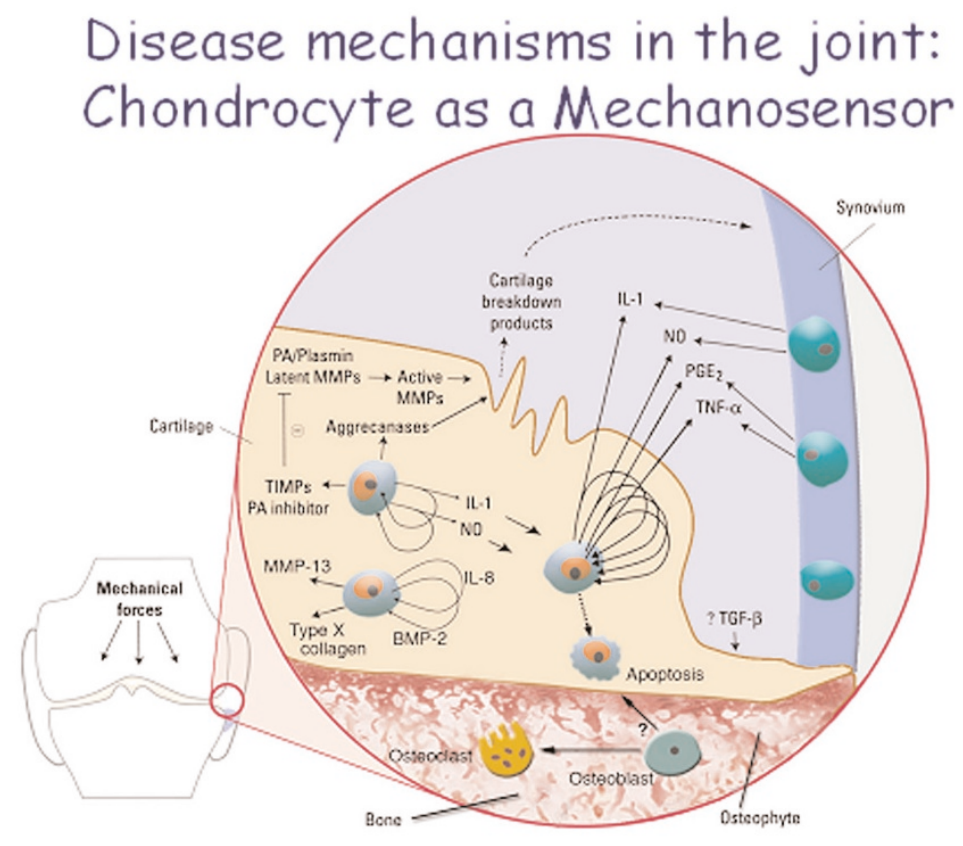

Molecular and cellular mechanisms that perpetuate osteoarthritis. BMP, bone morphogenetic protein; MMP, matrix metalloproteinase; NO, nitric oxide; PA, plasminogen activator; PG, prostaglandin; TGF, transforming growth factor; TIMP, tissue inhibitor of MMP; TNF, tumor necrosis factor. Adapted from Abramson and coworkers [79].

stress, changes in gene expression and an increase in production of inflammatory cytokines and matrix-degrading enzymes have been noted (Figure 1) [38]. The recognition that chondrocytes act as mechano-sensors and osmosensors has opened up the possibility that these proteins could serve as novel targets for disease-modifying OA drugs.

\section{Degeneration of articular cartilage in osteoarthritis: cartilage degradation}

$\mathrm{OA}$ is characterized by a loss of articular cartilage matrix, which is the result of the action of proteolytic enzymes that degrade both proteoglycans (aggrecanases) and collagen (collagenases). Native collagen has been shown to be cleaved by matrix metalloproteinase (MMP)-1, MMP-8, and MMP-13. Of the three major MMPs that degrade native collagen, MMP-13 may be the most important in OA because it preferentially degrades type II collagen [39] and it has also been shown that expression of MMP-13 greatly increases in OA [40]. Among the characteristic changes in $\mathrm{OA}$ cartilage is the development of the hypertrophic chondrocyte phenotype, characterized by increased production of MMP-13, type $\mathrm{X}$ collagen, and alkaline phosphatase. Kawaguchi [41] has provided evidence that the induction of the transcriptional activator Runx2 (runt-related transcription factor 2) under mechanical stress in turn induces the hypertrophic phenotype, which leads to type II collagen degradation (MMP-13 production), endochondral ossification, and chondrocyte apoptosis.
The aggrecanases belong to a family of extracellular proteases known as the ADAMTS (a disintegrin and metalloprotease with thrombospondin motifs) [39]. Two aggrecanases, ADAMTS-4 and ADAMTS-5, appear to be major enzymes in cartilage degradation in OA [40]. Recently, an ADAMTS-5 knock-out mouse and ADAMTS-5-resistant aggrecan knockin mouse, both of which show protection from $O A$, have validated ADAMTS-5 as a target for OA $[42,43]$.

IL-1 stimulates the synthesis and secretion of many degradative enzymes in cartilage, including latent collagenase, latent stromelysin, latent gelatinase, and tissue plasminogen activator [44]. The balance of active and latent enzymes is regulated by at least two enzyme inhibitors: tissue inhibitor of metalloproteinases and plasminogen activator inhibitor-1 [45]. These enzyme inhibitors are synthesized in increased amounts under the regulation of TGF- $\beta$.

\section{Degeneration of articular cartilage in osteoarthritis: cartilage synthesis}

The metabolic imbalance in OA includes both an increase in cartilage degradation and an insufficient reparative or anabolic response. The identification of anabolic agents that can be utilized to restore cartilage is an area of significant investigation. Molecules of interest include cartilage anabolic factors such as bone morphogenetic proteins, insulin-like growth factor-I, TGF- $\beta$, and fibroblast growth factors. Growth factors such as bone morphogenetic proteins have the ability 
to reverse catabolic responses by IL-1 [46]. Conversely, normal chondrocytes exposed to IL-1 or chondrocytes from OA patients exhibit decreased responsiveness to growth factors [47]. An understanding of the interaction between catabolic cytokines and anabolic growth factors could lead to the identification of molecules that restore the responsiveness of diseased chondrocytes to anabolic growth factors or inhibitors of inflammatory cytokines.

\section{Degeneration of articular cartilage in osteoarthritis: inflammation}

The role played by inflammatory cytokines and mediators produced by joint tissues in the pathogenesis of OA is attracting increased attention. Among the many biochemical pathways that are activated within joint tissues during the course of OA are mediators classically associated with inflammation, notably $\mathrm{IL}-1 \beta$ and tumor necrosis factor (TNF)- $\alpha$. These cytokines, in an autocrine/paracrine manner, stimulate their own production and induce chondrocytes to produce proteases, chemokines, nitric oxide, and eicosanoids such as prostaglandins and leukotrienes. The action of these inflammatory mediators within cartilage is predominantly to drive catabolic pathways, inhibit matrix synthesis, and promote cellular apoptosis. Thus, although $O A$ is not conventionally considered an inflammatory arthritis, that concept - based historically on the numbers of leukocytes in synovial fluid - should be reconsidered. Indeed, 'inflammatory' mediators perpetuate disease progression and therefore represent potential targets for disease modification.

\section{Cytokines and chemokines}

As noted above, a characteristic feature of established $O A$ is increased production of pro-inflammatory cytokines, such as $\mathrm{IL}-1 \beta$ and TNF- $\alpha$, by articular chondrocytes. Both IL-1 $\beta$ and TNF- $\alpha$ exert comparable catabolic effects on chondrocyte metabolism, decreasing proteoglycan collagen synthesis and increasing aggrecan release via the induction of degradative proteases [48]. IL-1 $\beta$ and TNF- $\alpha$ also induce chondrocytes and synovial cells to produce other inflammatory mediators, such as IL-8, IL-6, nitric oxide, and prostaglandin $\mathrm{E}_{2}$. The actions of both cytokines are in part mediated by activation of the transcription factor nuclear factor- $\kappa \mathrm{B}$, which further increases their own expression and that of other catabolic proteins such as inducible nitric oxide synthase (iNOS) and COX-2, thus creating an autocatalytic cascade that promotes self-destruction of articular cartilage [49].

IL-1 $\beta$ and TNF- $\alpha$ are both synthesized intracellularly as precursors, converted through proteolytic cleavage to their mature forms by caspases - membrane-bound IL-1 $\beta$-converting enzyme (ICE) and TNF- $\alpha$-converting enzyme (TACE) - and released extracellularly in their active forms. The expression of both ICE and TACE has been shown to be upregulated in OA cartilage [50]. Inhibitors of both ICE and TACE are of interest as future therapeutic small-molecule antagonists of downstream IL-1 $\beta$ and TNF- $\alpha$ expression, respectively; studies with an ICE inhibitor are now underway in two murine models.
Osteoarthritic cartilage is also the site of increased production of both $\mathrm{C}-\mathrm{X}-\mathrm{C}$ and $\mathrm{C}-\mathrm{C}$ chemokines. These include IL-8, monocyte chemoattractant protein-1, and RANTES (regulated on activation, normal T-cell expressed and secreted; also known as C-C chemokine ligand-5), as well as the receptors C-C chemokine receptor (CCR)-2 and CCR-5 [51]. RANTES induces expression of its own receptor, CCR-5, which suggests an autocrine/paracrine pathway of the chemokine within the cartilage. Monocyte chemoattractant protein-1 and RANTES promote chondrocyte catabolic activities, including induction of nitric oxide synthase, increased MMP-3 expression, inhibition of proteoglycan synthesis, and enhancement of proteoglycan release.

\section{Prostaglandins}

Chondrocytes from human OA cartilage explants express COX-2 and spontaneously produce prostaglandin $E_{2}$ [52]. We have recently reported that prostaglandin $E_{2}$ produced by OA cartilage explants decreases proteoglycan synthesis and enhances the degradation of both aggrecan and type II collagen. These effects are associated with downregulation of MMP-1 and upregulation of MMP-13 and ADAMTS-5, and are mediated via engagement of the prostaglandin $E$ receptor 4 (EP4) [53]. How the divergent synthesis of MMP-1 and MMP-13 is regulated remains unknown, but we previously reported that upregulation of the nuclear orphan receptor NURR1 (NR4A2) in OA cartilage causes similar divergent effects. This suggests that the effect of prostaglandin $E_{2}$ on MMP-1 and MMP-13 may be a result of NURR1 activation (NR4A2) [54]. In their interesting recent report of a genomewide scan, Valdes and coworkers [18] identified a COX-2 variant that was associated with increased risk for knee OA a finding that underscores the possible importance of this signaling pathway in the pathogenesis of knee OA.

\section{Reactive oxygen species}

Among the inflammatory mediators that are of interest in the pathogenesis of $\mathrm{OA}$ are both oxygen and nitrogen-derived free radicals. Reactive oxygen species such as superoxide anion, hydrogen peroxide, and hydroxyl radicals directly promote chondrocyte apoptosis, most probably via mitochondrial dysfunction $[55,56]$.

\section{Nitric oxide}

Nitric oxide, produced by the inducible isoform of nitric oxide synthase (iNOS), is a major catabolic factor produced by chondrocytes in response to pro-inflammatory cytokines such as IL-1 $\beta$ and TNF- $\alpha$ [57]. Considerable evidence indicates that the overproduction of nitric oxide by chondrocytes plays a role in the perpetuation of cartilage destruction in OA. Although normal cartilage does not express iNOS or produce nitric oxide without stimulation by cytokines such as IL-1, OA cartilage explants spontaneously produce large amounts of nitric oxide [58].

Nitric oxide exerts multiple effects on chondrocytes that promote articular cartilage degradation [57]. These include 
inhibition of collagen and proteoglycan synthesis; activation of metalloproteinases; increased susceptibility to injury by other oxidants (for example, hydrogen peroxide); and apoptosis. Several studies have implicated nitric oxide as an important mediator in chondrocyte apoptosis, a feature that is common in progressive OA. There is evidence that apoptosis results from the formation of peroxynitrite, a toxic free radical produced by the reaction of nitric oxide and superoxide anion [59].

Nitric oxide and its derivatives may also play protective roles, however, because protease activity and proteoglycan degradation are enhanced when nitric oxide production is blocked [60]. In murine models the development of surgically induced OA can be accelerated in mice that are knocked out for IL-1 $\beta$, IL-1-converting enzyme, or iNOS. This suggests that a certain level of these molecules may be necessary to maintain a healthy joint and that complete pharmacologic suppression may be detrimental [61]. The protective roles played by nitric oxide in multiple cell types may reflect differing properties of the redox form of the molecule produced in the microenvironment [62].

\section{Abnormalities of bone}

Osteophyte formation and sclerosis of subchondral bone are hallmarks of OA. It has been theorized that osteophytes occur as a result of penetration of blood vessels into the basal layers of degenerating cartilage, or as a result of abnormal healing of stress fractures in the subchondral trabeculae near the joint margins [63]. TGF- $\beta$, when introduced into the joint in experimental animals, induces osteophyte formation, and TGF- $\beta$ expression is observed in osteophytes in patients with OA $[64,65]$.

With regard to subchondral bone sclerosis, it has been suggested that excessive loads may cause microfractures of subchondral trabeculae that heal via callus formation and remodeling. Whether subchondral sclerosis precedes the onset of OA or is a change that occurs but is not required for cartilage degeneration is not known. However, strategies targeted at bone disorders such as osteoporosis, and molecular targets that alter osteoclast and/or osteoblast function may represent opportunities to modulate pathologic subchondral changes in OA, and are therefore under consideration in efforts to develop disease-modifying treatments.

\section{Bone marrow lesions}

Felson and coworkers [66] reported that medial bone marrow lesions observed on magnetic resonance imaging (MRI) are associated with both knee pain and the risk for disease progression. However, it should be noted that, depending on size and location, the significance of bone marrow lesions in the individual patient might vary. The presence of bone marrow lesions and their relation to progression has been explained in part by an association with limb alignment [66]. The histopathologic nature of bone marrow lesions in $\mathrm{OA}$ is not yet clear, and it is probable that a number of tissue abnormalities such as microfractures, cysts, and avascular necrosis may contribute to the MRI findings.

\section{Synovial proliferation and inflammation}

It is increasingly appreciated that some degree of synovitis may be observed even in early OA [67]. Synovial histologic changes include synovial hypertrophy and hyperplasia, with an increased number of lining cells, often accompanied by infiltration of the sublining tissue with scattered foci of lymphocytes [68]. Synovitis is often localized and may be asymptomatic. Arthroscopic studies suggest that localized proliferative and inflammatory changes of the synovium occur in up to $50 \%$ of OA patients, and the activated synovium may produce proteases and cytokines that accelerate progression of disease [69]. Cartilage breakdown products, derived from the articular surface as a result of mechanical or enzymatic destruction of the cartilage, can provoke the release of collagenase and other hydrolytic enzymes from synovial cells and macrophages. Cartilage breakdown products are also believed to result in mononuclear cell infiltration and vascular hyperplasia in the synovial membrane in OA. A consequence of these low-grade inflammatory processes is the induction of synovial IL- $1 \beta$ and TNF- $\alpha$, which are probable contributors to the degradative cascade. There are also reports of increased numbers of immune cells in synovial tissue, such as activated $\mathrm{B}$ cells and $\mathrm{T}$ lymphocytes, including evidence for a clonally expanded, antigen-driven B-cell response that may contribute to the development or progression of the disease [70].

\section{Biomarkers}

Among the more exciting advances in our understanding of $\mathrm{OA}$ has come from the study of imaging and chemical biomarkers, which have revealed new aspects about the pathogenesis and progression of the disease.

\section{Imaging biomarkers}

Although conventional radiography is useful for the diagnosis of established disease, it has shortcomings with respect to the assessment of progressive disease. For example radiographic images are insensitive to early change within cartilage and bone and do not reveal synovial or meniscal pathology. They also lack correlation with severity of symptoms and are nonspecific measures of disease progression. The potential value of MRI as a 'biomarker' has been illustrated by studies that indicate that the presence of either bone marrow lesions [66] or meniscal disease [71] predict patients with knee $\mathrm{OA}$ at higher risk for disease progression. Techniques for the quantitative and functional assessment of cartilage, synovium, and bone by MRI are advancing, making it likely that MRI will eventually replace conventional radiology as a more sensitive and specific measure of disease progression [66,72]. In addition, functional MRI studies (delayed gadolinium-enhanced MRI of cartilage or sodium MRI), which detect biochemical changes of extracellular matrix proteins in cartilage, have attracted great interest as 'proof of mechanism' biomarkers that might demonstrate in 
Table 1

\begin{tabular}{|c|c|c|c|c|}
\hline Tissue & Molecule & Markers of synthesis & Markers of degradation & BIPED classification \\
\hline \multirow[t]{4}{*}{ Bone } & Type I collagen & & PYDa & $\mathrm{B}$ \\
\hline & & & NTX-ןa,b & $\mathrm{D}$ \\
\hline & & & CTX-|a,b & $\mathrm{P}$ \\
\hline & Noncollagenous proteins & Osteocalcin ${ }^{b}$ & & $\mathrm{P}$ \\
\hline \multirow[t]{14}{*}{ Cartilage } & Type II collagen & PIIANPb & & $\mathrm{P}$ \\
\hline & & Total PIINP & & $\mathrm{D}$ \\
\hline & & $\mathrm{PlICPb,c}$ & & $\mathrm{D}, \mathrm{P}$ \\
\hline & & & CTX-\|a,c & $\mathrm{D}, \mathrm{B}, \mathrm{P}, \mathrm{E}$ \\
\hline & & & HELIX-Ila & $\mathrm{P}$ \\
\hline & & & Coll 2-1 ${ }^{a, b}$ & $\mathrm{P}$ \\
\hline & & & Coll 2-1 $\mathrm{NO}_{2}{ }^{\mathrm{a}, \mathrm{b}}$ & $\mathrm{P}$ \\
\hline & & & $\mathrm{C} 2 \mathrm{C}^{\mathrm{a}, \mathrm{b}}$ & $P, E$ \\
\hline & & & $1,2 \mathrm{C}^{\mathrm{a}, \mathrm{b}}$ & $P, E$ \\
\hline & Aggrecan & $\begin{array}{l}\text { Epitope } 846 \text { (cartilage } \\
\text { contentc) }\end{array}$ & & $E$ \\
\hline & $\begin{array}{l}\text { Nonaggrecan and } \\
\text { noncollagenous proteins }\end{array}$ & & $\mathrm{COMPb,c}$ & $D, B, P$ \\
\hline & & & Pentosidine ${ }^{a, b}$ & $\mathrm{P}$ \\
\hline & Proteases and their inhibitors & & MMPs ${ }^{b}$ & $B, P, E$ \\
\hline & & & TIMPs $^{b}$ & $\mathrm{~B}, \mathrm{P}$ \\
\hline \multirow[t]{3}{*}{ Synovium } & Type III collagen & & Glc-Gal-PYDa & $E$ \\
\hline & Noncolagenous proteins & YKL-40b,c & & $\mathrm{B}, \mathrm{E}$ \\
\hline & & Hayluronic acidb & & $\mathrm{B}, \mathrm{P}$ \\
\hline
\end{tabular}

aUrine. bSerum. ' Synovial fluid. BIPED, B (burden of disease), I (investigative), P (prognostic), E (efficacy of intervention), D (diagnostic); C1,2C, assay that detects COL2-3/4C (short) epitope; C2C, assay that detects COL2-3/4C (long) epitope; Coll 2-1, 9-amino-acid peptide of type II collagen; Coll 2-1 $\mathrm{NO}_{2}$, nitrated form of Coll 2-1; COMP, cartilage oligomeric protein; CTX-I, carboxyl-terminal cross-linked telopeptide of type I collagen; CTX-II, C-terminal cross-linked telopeptide of type II collagen; Glc-Gal-PYD, glucosyl-galactosyl-pyridinoline; HELIX-II, helical type II collagen; MMP, matrix metalloproteinase; NTX-I, N-terminal cross-linked telopeptide of type I collagen; PIIANP, N-propeptide IIA of collagen type II; PIICP, C-propeptide of collagen type II; PIINP, N-propeptide II of collagen type II; PYD, pyridinoline; TIMP, tissue inhibitor of matrix metalloproteinase; YKL-40, cartilage glycoprotein 39. Reproduced with permission from Rouseeau and Delmas [80].

the short term (4 to 6 weeks) that a treatment restores normal chondrocyte metabolism.

\section{Biochemical markers}

It is likely that biochemical markers will be used in conjunction with imaging in order to establish stage of disease, predict progression, and assess disease activity and progression in OA. The Osteoarthritis Biomarkers Network, a consortium of five National Institutes of Health-designated sites, has recently proposed a classification scheme of biomarkers for $\mathrm{OA}$ [73]. Five categories of biomarkers (captured in the acronym BIPED) were proposed to aid the study of all aspects of OA, from basic science research to clinical trials (Table 1): burden of disease, investigative, prognostic, efficacy of intervention, and diagnostic.

Burden of disease markers denote severity or extent of disease in one or multiple joints. Some examples that are elevated in populations of patients with hip or knee OA include serum COMP, urinary carboxyl-terminal cross-linking telopeptide of type II collagen (CTX-II), and serum hyaluronan [74]. Candidate prognostic markers include serum COMP, urinary CTX-II, serum hyaluronic acid [75], and pentosidine, an advanced glycation end-product [76]. The available data suggest that urinary CTX-II is of particular interest. Elevated levels of CTX-II have also been found to predict progression of joint space narrowing in both knee and hip OA. Moreover, Garnero and coworkers [77] found that bone marrow abnormalities on MRI significantly correlated with urine CTX-II and that patients with highest baseline urinary CTX-II levels were more likely to have worsening bone marrow abnormalities at 3 months. Finally, urinary CTX-II increases after menopause, consistent with the acceleration of OA in postmenopausal women and raising an intriguing question about the protective effect of estrogens in OA.

It should be noted, however, the predictive value of these markers in clinical trials has yet to be proven and, as such, 


\section{The Scientific Basis of Rheumatology: A Decade of Progress}

This article is part of a special collection of reviews, The Scientific Basis of Rheumatology: A Decade of Progress, published to mark Arthritis Research \& Therapy's 10th anniversary.

Other articles in this series can be found at: http://arthritis-research.com/sbr

there remains a need to validate these and other new biomarkers. Indeed, caution regarding the predictive value of drug-induced declines in CTX-II has been raised by Bingham and coworkers [78], who reported that risedronate decreases biochemical markers of cartilage degradation but does not decrease symptoms or slow radiographic progression in patients with medial compartment OA of the knee.

\section{Conclusion}

During the past decade there have been significant developments in the scientific understanding of OA. Aided by advances in imaging technology, we have come to appreciate that $\mathrm{OA}$ is a disease of the 'whole joint', which involves a complex series of molecular changes at the cell, matrix, and tissue levels and complex interactions between the tissues that make up the joint. We are beginning to understand better the mechanisms by which genetic, mechanical, and metabolic risk factors initiate and perpetuate the biochemical changes that lead to progressive failure of the joint. We are also gaining a better appreciation of the processes of aging and senescence that underlie disease mechanisms. These discoveries have opened opportunities for the identification of targets for therapeutic intervention, which hopefully will lead to effective therapies that reduce the symptoms and slow the progression of OA.

\section{Competing interests}

The authors declare that they have no competing interests.

\section{References}

1. Kellgren JH, Lawrence JS, Bier F: Genetic factors in generalized osteo-arthrosis. Ann Rheum Dis 1963, 22:237-255.

2. Zhai G, Hart DJ, Kato BS, MacGregor A, Spector TD: Genetic influence on the progression of radiographic knee osteoarthritis: a longitudinal twin study. Osteoarthritis Cartilage 2007, 15:222-225.

3. Valdes AM, Doherty M, Spector TD: The additive effect of individual genes in predicting risk of knee osteoarthritis. Ann Rheum Dis 2008, 67:124-127.

4. Holderbaum D, Haqqi TM, Moskowitz RW: Genetics and osteoarthritis: exposing the iceberg. Arthritis Rheum 1999, 42:397-405.

5. Mier RJ, Holderbaum D, Ferguson R, Moskowitz R: Osteoarthritis in children associated with a mutation in the type II procollagen gene (COL2A1). Mol Genet Metab 2001, 74:338-341.
6. Reginato $A M$, Olsen BR: The role of structural genes in the pathogenesis of osteoarthritic disorders. Arthritis Res 2002, 4: 337-345.

7. Ikegawa S: New gene associations in osteoarthritis: what do they provide, and where are we going? Curr Opin Rheumatol 2007, 19:429-434.

8. Miyamoto Y, Shi D, Nakajima M, Ozaki K, Sudo A, Kotani A, Uchida A, Tanaka T, Fukui N, Tsunoda T, Takahashi A, Nakamura Y, Jiang Q, lkegawa S: Common variants in DVWA on chromosome 3p24.3 are associated with susceptibility to knee osteoarthritis. Nat Genet 2008, 40:994-998.

9. Atif U, Philip A, Aponte J, Woldu EM, Brady S, Kraus VB, Jordan JM, Doherty M, Wilson AG, Moskowitz RW, Hochberg M, Loeser $\mathrm{R}$, Renner JB, Chiano M: Absence of association of asporin polymorphisms and osteoarthritis susceptibility in US Caucasians. Osteoarthritis Cartilage 2008, 16:1174-1177.

10. Valdes AM, Spector TD, Doherty S, Wheeler M, Hart DJ, Doherty M: Association of the DVWA and GDF5 polymorphisms with osteoarthritis in UK populations. Ann Rheum Dis 2008 [Epub ahead of print].

11. Vaes RB, Rivadeneira F, Kerkhof JM, Hofman A, Pols HA, Uitterlinden AG, van Meurs JB: Genetic variation in the GDF5 region is associated with osteoarthritis, height, hip axis length and fracture risk: the Rotterdam study. Ann Rheum Dis 2008 [Epub ahead of print].

12. Kerkhof JM, Uitterlinden AG, Valdes AM, Hart DJ, Rivadeneira F, Jhamai M, Hofman A, Pols HA, Bierma-Zeinstra SM, Spector TD, van Meurs JB: Radiographic osteoarthritis at three joint sites and FRZB, LRP5, and LRP6 polymorphisms in two populationbased cohorts. Osteoarthritis Cartilage 2008, 16:1141-1149.

13. Dabovic B, Chen Y, Colarossi C, Zambuto L, Obata H, Rifkin DB: Bone defects in latent TGF-beta binding protein (Ltbp)-3 null mice; a role for Ltbp in TGF-beta presentation. J Endocrinol 2002, 175:129-141.

14. Blair-Levy JM, Watts CE, Fiorentino NM, Dimitriadis EK, Marini JC, Lipsky PE: A type I collagen defect leads to rapidly progressive osteoarthritis in a mouse model. Arthritis Rheum 2008, 58:1096-1106.

15. Valdes AM, Spector TD: The contribution of genes to osteoarthritis. Rheum Dis Clin North Am 2008, 34:581-603.

16. Loughlin J, Dowling B, Mustafa Z, Chapman K: Association of the interleukin-1 gene cluster on chromosome 2 q13 with knee osteoarthritis. Arthritis Rheum 2002, 46:1519-1527.

17. Bukowski J, Wang H, Aziz N, Krasnokutsky S, Samuels J, Greenberg J, Kraus VB, McDaniel G, Abramson S, Attur M: IL-1 RN Polymorphisms are associated with radiographic severity in osteoarthritis. Osteoarthritis Cartilage 2008, 16(suppl 4):S34.

18. Valdes AM, Loughlin J, Timms KM, van Meurs JJ, Southam L, Wilson SG, Doherty S, Lories RJ, Luyten FP, Gutin A, Abkevich V, Ge D, Hofman A, Uitterlinden AG, Hart DJ, Zhang F, Zhai G, Egli RJ, Doherty M, Lanchbury J, Spector TD: Genome-wide association scan identifies a prostaglandin-endoperoxide synthase 2 variant involved in risk of knee osteoarthritis. Am J Hum Genet 2008, 82:1231-1240.

19. Martin JA, Buckwalter JA: Aging, articular cartilage chondrocyte senescence and osteoarthritis. Biogerontology 2002, 3:257-264.

20. Todd Allen R, Robertson CM, Harwood FL, Sasho T, Williams SK, Pomerleau AC, Amiel D: Characterization of mature vs aged rabbit articular cartilage: analysis of cell density, apoptosisrelated gene expression and mechanisms controlling chondrocyte apoptosis. Osteoarthritis Cartilage 2004, 12:917-923.

21. Robertson CM, Pennock AT, Harwood FL, Pomerleau AC, Allen RT, Amiel D: Characterization of pro-apoptotic and matrixdegradative gene expression following induction of osteoarthritis in mature and aged rabbits. Osteoarthritis Cartilage 2006, 14:471-476.

22. Anderson JJ, Felson DT: Factors associated with osteoarthritis of the knee in the first national Health and Nutrition Examination Survey (HANES I). Evidence for an association with overweight, race, and physical demands of work. Am J Epidemiol 1988, 128:179-189.

23. Leach RE, Baumgard S, Broom J: Obesity: its relationship to osteoarthritis of the knee. Clin Orthop Relat Res 1973, 93:271273.

24. Dumond $H$, Presle N, Terlain B, Mainard D, Loeuille D, Netter P Pottie P: Evidence for a key role of leptin in osteoarthritis. Arthritis Rheum 2003, 48:3118-3129. 
25. Hunter DJ, Niu J, Felson DT, Harvey WF, Gross KD, McCree P, Aliabadi $P$, Sack B, Zhang Y: Knee alignment does not predict incident osteoarthritis: the Framingham osteoarthritis study. Arthritis Rheum 2007, 56:1212-1218.

26. Sharma L: The role of varus and valgus alignment in knee osteoarthritis. Arthritis Rheum 2007, 56:1044-1047.

27. Sharma L, Lou C, Cahue S, Dunlop DD: The mechanism of the effect of obesity in knee osteoarthritis: the mediating role of malalignment. Arthritis Rheum 2000, 43:568-575.

28. Hunter DJ, Zhang Y, Niu J, Goggins J, Amin S, LaValley MP, Guermazi A, Genant H, Gale D, Felson DT: Increase in bone marrow lesions associated with cartilage loss: a longitudinal magnetic resonance imaging study of knee osteoarthritis. Arthritis Rheum 2006, 54:1529-1535.

29. Bullough PG: The geometry of diarthrodial joints, its physiologic maintenance, and the possible significance of age-related changes in geometry-to-load distribution and the development of osteoarthritis. Clin Orthop Relat Res 1981, 156:61-66.

30. Wluka AE, Cicuttini FM, Spector TD: Menopause, oestrogens and arthritis. Maturitas 2000, 35:183-199.

31. Richmond RS, Carlson CS, Register TC, Shanker G, Loeser RF: Functional estrogen receptors in adult articular cartilage: estrogen replacement therapy increases chondrocyte synthesis of proteoglycans and insulin-like growth factor binding protein 2. Arthritis Rheum 2000, 43:2081-2090.

32. Nevitt MC, Cummings SR, Lane NE, Hochberg MC, Scott JC, Pressman AR, Genant HK, Cauley JA: Association of estrogen replacement therapy with the risk of osteoarthritis of the hip in elderly white women. Study of Osteoporotic Fractures Research Group. Arch Internal Med 1996, 156:2073-2080.

33. Sniekers $Y H$, Weinans $H$, Bierma-Zeinstra SM, van Leeuwen JP, van Osch GJ: Animal models for osteoarthritis: the effect of ovariectomy and estrogen treatment: a systematic approach. Osteoarthritis Cartilage 2008, 16:533-541.

34. Nevitt MC, Felson DT, Williams EN, Grady D: The effect of estrogen plus progestin on knee symptoms and related disability in postmenopausal women: The Heart and Estrogen/Progestin Replacement Study, a randomized, double-blind, placebo-controlled trial. Arthritis Rheum 2001, 44:811-818.

35. Meredith D, Gehl KA, Seymour J, Ellory JC, Wilkins RJ: Characterization of sulphate transporters in isolated bovine articular chondrocytes. J Orthop Res 2007, 25:1145-1153.

36. Sanchez JC, Powell T, Staines HM, Wilkins RJ: Electrophysiological demonstration of voltage- activated $\mathrm{H}^{+}$channels in bovine articular chondrocytes. Cell Physiol Biochem 2006, 18: 85-90.

37. Bengtsson T, Aszodi A, Nicolae C, Hunziker EB, Lundgren-Akerlund E, Fassler R: Loss of alpha10beta1 integrin expression leads to moderate dysfunction of growth plate chondrocytes. $J$ Cell Sci 2005, 118:929-936.

38. Fermor B, Weinberg JB, Pisetsky DS, Misukonis MA, Banes AJ, Guilak F: The effects of static and intermittent compression on nitric oxide production in articular cartilage explants. J Orthop Res 2001, 19:729-737.

39. Knauper V, Lopez-Otin C, Smith B, Knight G, Murphy G: Biochemical characterization of human collagenase-3. J Biol Chem 1996, 271:1544-1550.

40. Tetlow LC, Adlam DJ, Woolley DE: Matrix metalloproteinase and proinflammatory cytokine production by chondrocytes of human osteoarthritic cartilage: associations with degenerative changes. Arthritis Rheum 2001, 44:585-594

41. Kawaguchi $\mathrm{H}$ : Endochondral ossification signals in cartilage degradation during osteoarthritis progression in experimental mouse models. Mol Cells 2008, 25:1-6.

42. Tang BL: ADAMTS: a novel family of extracellular matrix proteases. Int J Biochem Cell Biol 2001, 33:33-44.

43. Arner EC: Aggrecanase-mediated cartilage degradation. Curr Opin Pharmacol 2002, 2:322-329.

44. Glasson SS, Askew R, Sheppard B, Carito B, Blanchet T, Ma HL, Flannery CR, Peluso D, Kanki K, Yang Z, Majumdar MK, Morris EA: Deletion of active ADAMTS5 prevents cartilage degradation in a murine model of osteoarthritis. Nature 2005, 434:644648.

45. Kandel RA, Dinarello CA, Biswas C: The stimulation of collagenase production in rabbit articular chondrocytes by interleukin-1 is increased by collagens. Biochem Int 1987, 15: 1021-1031.
46. Majumdar MK, Wang E, Morris EA: BMP-2 and BMP-9 promotes chondrogenic differentiation of human multipotential mesenchymal cells and overcomes the inhibitory effect of IL-1. J Cell Physiol 2001, 189:275-284.

47. Kaiser M, Haag J, Soder S, Bau B, Aigner T: Bone morphogenetic protein and transforming growth factor beta inhibitory Smads 6 and 7 are expressed in human adult normal and osteoarthritic cartilage in vivo and are differentially regulated in vitro by interleukin-1beta. Arthritis Rheum 2004, 50:35353540.

48. Pelletier JP, Martel-Pelletier J, Abramson SB: Osteoarthritis, an inflammatory disease: potential implication for the selection of new therapeutic targets. Arthritis Rheum 2001, 44:12371247.

49. Lianxu C, Hongti J, Changlong Y: NF-kappaBp65-specific siRNA inhibits expression of genes of COX-2, NOS-2 and MMP-9 in rat IL-1 beta-induced and TNF-alpha-induced chondrocytes. Osteoarthritis Cartilage 2006, 14:367-376.

50. Patel IR, Attur MG, Patel RN, Stuchin SA, Abagyan RA, Abramson $\mathrm{SB}$, Amin AR: TNF-alpha convertase enzyme from human arthritis-affected cartilage: isolation of cDNA by differential display, expression of the active enzyme, and regulation of TNF-alpha. J Immunol 1998, 160:4570-4579.

51. Alaaeddine N, Olee T, Hashimoto S, Creighton-Achermann L, Lotz $\mathrm{M}$ : Production of the chemokine RANTES by articular chondrocytes and role in cartilage degradation. Arthritis Rheum 2001, 44:1633-1643.

52. Amin AR, Attur M, Patel RN, Thakker GD, Marshall PJ, Rediske J, Stuchin SA, Patel IR, Abramson SB: Superinduction of cyclooxygenase-2 activity in human osteoarthritis-affected cartilage. Influence of nitric oxide. J Clin Invest 1997, 99:12311237.

53. Attur M, Al-Mussawir HE, Patel J, Kitay A, Dave M, Palmer G, Pillinger $\mathrm{MH}$, Abramson SB: Prostaglandin E2 exerts catabolic effects in osteoarthritis cartilage: evidence for signaling via the EP4 receptor. J Immuno/ 2008, 181:5082-5088.

54. Mix KS, Attur MG, Al-Mussawir H, Abramson SB, Brinckerhoff CE, Murphy EP: Transcriptional repression of matrix metalloproteinase gene expression by the orphan nuclear receptor NURR1 in cartilage. J Biol Chem 2007, 282:9492-9504.

55. Afonso V, Champy R, Mitrovic D, Collin P, Lomri A: Reactive oxygen species and superoxide dismutases: role in joint diseases. Joint Bone Spine 2007, 74:324-329.

56. Kim HA, Blanco FJ: Cell death and apoptosis in osteoarthritic cartilage. Curr Drug Targets 2007, 8:333-345.

57. Scher JU, Pillinger MH, Abramson SB: Nitric oxide synthases and osteoarthritis. Curr Rheumatol Rep 2007, 9:9-15.

58. Amin AR, Di Cesare PE, Vyas P, Attur M, Tzeng E, Billiar TR, Stuchin SA, Abramson SB: The expression and regulation of nitric oxide synthase in human osteoarthritis-affected chondrocytes: evidence for up-regulated neuronal nitric oxide synthase. J Exp Med 1995, 182:2097-2102.

59. Loeser RF, Carlson CS, Del Carlo M, Cole A: Detection of nitrotyrosine in aging and osteoarthritic cartilage: correlation of oxidative damage with the presence of interleukin-1beta and with chondrocyte resistance to insulin-like growth factor 1. Arthritis Rheum 2002, 46:2349-2357.

60. Clements KM, Burton-Wurster N, Lust G: The spread of cell death from impact damaged cartilage: lack of evidence for the role of nitric oxide and caspases. Osteoarthritis Cartilage 2004, 12:577-585.

61. Clements KM, Price JS, Chambers MG, Visco DM, Poole AR, Mason RM: Gene deletion of either interleukin-1beta, interleukin-1beta-converting enzyme, inducible nitric oxide synthase, or stromelysin 1 accelerates the development of knee osteoarthritis in mice after surgical transection of the medial collateral ligament and partial medial meniscectomy. Arthritis Rheum 2003, 48:3452-3463.

62. Abramson SB: Nitric oxide in inflammation and pain associated with osteoarthritis. Arthritis Res Ther 2008, 10(suppl 2): S2.

63. Gilbertson EM: Development of periarticular osteophytes in experimentally induced osteoarthritis in the dog. A study using microradiographic, microangiographic, and fluorescent bone-labelling techniques. Ann Rheum Dis 1975, 34:12-25.

64. Bakker $A C$, van de Loo FA, van Beuningen $H M$, Sime $P$, van Lent $\mathrm{PL}$, van der Kraan PM, Richards CD, van den Berg WB: Overex- 
pression of active TGF-beta-1 in the murine knee joint: evidence for synovial-layer-dependent chondro-osteophyte formation. Osteoarthritis Cartilage 2001, 9:128-136.

65. Uchino M, Izumi T, Tominaga T, Wakita R, Minehara H, Sekiguchi $\mathrm{M}$, Itoman M: Growth factor expression in the osteophytes of the human femoral head in osteoarthritis. Clin Orthop Relat Res 2000, 377:119-125.

66. Felson DT, McLaughlin S, Goggins J, LaValley MP, Gale ME, Totterman S, Li W, Hill C, Gale D: Bone marrow edema and its relation to progression of knee osteoarthritis. Ann Intern Med 2003, 139:330-336

67. Benito MJ, Veale DJ, FitzGerald O, van den Berg WB, Bresnihan $B$ : Synovial tissue inflammation in early and late osteoarthritis. Ann Rheum Dis 2005, 64:1263-1267.

68. Rollin R, Marco F, Jover JA, Garcia-Asenjo JA, Rodriguez L, LopezDuran L, Fernandez-Gutierrez B: Early lymphocyte activation in the synovial microenvironment in patients with osteoarthritis: comparison with rheumatoid arthritis patients and healthy controls. Rheumatol Int 2008, 28:757-764.

69. Ayral X, Pickering EH, Woodworth TG, Mackillop N, Dougados M: Synovitis: a potential predictive factor of structural progression of medial tibiofemoral knee osteoarthritis - results of a 1 year longitudinal arthroscopic study in $\mathbf{4 2 2}$ patients. Osteoarthritis Cartilage 2005, 13:361-367.

70. Da RR, Qin Y, Baeten D, Zhang Y: B cell clonal expansion and somatic hypermutation of Ig variable heavy chain genes in the synovial membrane of patients with osteoarthritis. J Immunol 2007, 178:557-565.

71. Madan-Sharma R, Kloppenburg M, Kornaat PR, Botha-Scheepers SA, Le Graverand MP, Bloem JL, Watt I: Do MRI features at baseline predict radiographic joint space narrowing in the medial compartment of the osteoarthritic knee 2 years later? Skeletal Radiol 2008, 37:805-811.

72. Eckstein F, Burstein D, Link TM: Quantitative MRI of cartilage and bone: degenerative changes in osteoarthritis. NMR Biomed 2006, 19:822-854.

73. Bauer DC, Hunter DJ, Abramson SB, Attur M, Corr M, Felson D, Heinegård D, Jordan JM, Kepler TB, Lane NE, Saxne T, Tyree B, Kraus VB; Osteoarthritis Biomarkers Network: Classification of osteoarthritis biomarkers: a proposed approach. Osteoarthritis Cartilage 2006, 14:723-727.

74. Abramson S, Krasnokutsky S: Biomarkers in osteoarthritis. Bull NYU Hosp Jt Dis 2006, 64:77-81.

75. Garnero P: Use of biochemical markers to study and follow patients with osteoarthritis. Curr Rheumatol Rep 2006, 8:3744.

76. Senolt L, Braun M, Olejarova M, Forejtova S, Gatterova J, Pavelka $\mathrm{K}$ : Increased pentosidine, an advanced glycation end product, in serum and synovial fluid from patients with knee osteoarthritis and its relation with cartilage oligomeric matrix protein. Ann Rheum Dis 2005, 64:886-890.

77. Garnero P, Peterfy C, Zaim S, Schoenharting M: Bone marrow abnormalities on magnetic resonance imaging are associated with type II collagen degradation in knee osteoarthritis: a three-month longitudinal study. Arthritis Rheum 2005, 52:2822-2829.

78. Bingham CO III, Buckland-Wright JC, Garnero P, Cohen SB, Dougados M, Adami S, Clauw DJ, Spector TD, Pelletier JP, Raynauld JP, Strand V, Simon LS, Meyer JM, Cline GA, Beary JF: Risedronate decreases biochemical markers of cartilage degradation but does not decrease symptoms or slow radiographic progression in patients with medial compartment osteoarthritis of the knee: results of the two-year multinational knee osteoarthritis structural arthritis study. Arthritis Rheum 2006, 54:3494-3507.

79. Abramson SB, Attur M, Yazici Y: Prospects for disease modification in osteoarthritis. Nat Clin Pract Rheumatol 2006, 2:304312.

80. Rousseau JC, Delmas PD: Biologic markers in osteoarthritis. Nat Clin Pract Rheumato/ 2007, 3:347-356. 